\title{
Micronutrient-rich food consumption, intra-household food allocation and child stunting in rural Nigeria
}

\author{
Olusegun Fadare ${ }^{1, *}$, George Mavrotas ${ }^{1}$, Dare Akerele $^{2}$ and Motunrayo Oyeyemi ${ }^{1}$ \\ ${ }^{1}$ International Food Policy Research Institute, 1201 Eye Street NW, Washington, DC 20005-3915, USA: \\ ${ }^{2}$ Department of Agricultural Economics and Farm Management, Federal University of Agriculture, Abeokuta, Nigeria
}

Submitted 4 June 2018: Final revision received 5 September 2018: Accepted 2 0ctober 2018: First published online 3 December 2018

\begin{abstract}
Objective: Children from rural households are often deprived of adequate micronutrient intakes either from food or supplementation. The present study examines: (i) the determinants of households' micronutrient-rich food consumption; and (ii) the combined effect of vitamin A supplementation and micronutrientrich food consumption on child stunting in households with different food allocation patterns.

Design: Cross-sectional study. Households' micronutrient-rich food consumption frequency and vitamin A supplementation were used as a proxy measure for child micronutrient intakes. Intra-household food allocation patterns were assessed from caregivers' perception of the disparity in food distribution within the household. Descriptive statistics and logistic regression were employed in analysing the study's objectives.

Setting: Rural communities in Kwara State, Nigeria.

Participants: Included 419 children aged 6-59 months and 413 households.

Results: Owning small livestock and a refrigerator, knowledge of micronutrientrich foods and higher parental education had strong associations with households' micronutrient-rich food consumption. Children from households that consumed micronutrient-rich foods and received more diverse diets were less likely to experience stunting. The combined effect of micronutrient-rich food consumption and vitamin A supplementation was stronger on the likelihood of stunting reduction than the separate effect of each.

Conclusions: Assets ownership, human capital and knowledge of micronutrientrich foods improve consumption of micronutrient-rich foods among the study population. Micronutrient supplementation to children with poor access to micronutrient-rich foods may not substantially enhance child growth unless reinforced through consumption of micronutrient-rich foods. Fruit and vegetable gardening, livestock holdings and nutrition education to parents should be integral parts of community nutrition programming.
\end{abstract}

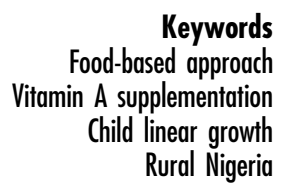

Global attention continues to focus on reducing stunting in children as a development agenda, especially in the African region ${ }^{(1)}$. Little progress has been made, however, in reducing the number of stunted children in Africa by $2025^{(2)}$. Nigeria is still among the countries with high burden of stunting among under-five children, with a national prevalence of about $32.9 \%$ and a much higher prevalence of $54.8 \%$ on average in the northern part of the country ${ }^{(3)}$. Closely linked with child malnutrition are diseases and inadequate dietary intakes ${ }^{(4)}$. Populations in most African countries consume diets that are nutritionally inadequate for child development ${ }^{(5,6)}$. For example in Nigeria, iodine, $\mathrm{Fe}, \mathrm{Zn}$ and vitamin A are generally suboptimal in staple $\operatorname{diets}^{(7)}$. Inadequate intakes of these essential micronutrients have many nutrition-related health consequences, especially for children. Therefore, increasing children's micronutrient intakes has been identified as a critical investment Africa must make for optimal child development and for sustainable development.

Inadequate micronutrient intakes over time result in many health issues for women and children, such as anaemia, childbirth, stillbirth, low-birth-weight babies and child stunting ${ }^{(8)}$. In recent years, micronutrient supplementation has gained prominence among strategies to improve micronutrient intakes among vulnerable populations in Africa. Several studies have provided evidence of 
the impact of $\mathrm{Zn}, \mathrm{Fe}$ and vitamin A supplementation programmes on child growth outcomes, with mixed evidence emanating from such studies ${ }^{(9-12)}$. These three micronutrients are generally associated with fetal development and child growth, of which Fe and vitamin $\mathrm{A}$ are the most important and most deficient in children ${ }^{(13,14)}$. Low intake of Fe causes Fe-deficiency anaemia mainly in women and pre-school children, while prolonged deprivation of vitamin A intake reduces immunity and makes children susceptible to infectious diseases such as measles, diarrhoea, chickenpox and respiratory infections. Vitamin A deficiency slows down children's bone development and cognitive performance, especially when combined with $\mathrm{Zn}$ deficiency ${ }^{(12,15)}$. Whereas micronutrient supplementation for children is justifiable in its own rights, whether this can significantly promote child growth in households with poor access to micronutrient-rich foods is unknown or less studied in Nigeria. An attempt to examine the disaggregated as well as the combined effects of micronutrient supplementation and consumption of micronutrient-rich foods on child nutritional status is therefore critical for policy action on child nutritional wellbeing.

Many factors have been identified as determinants of micronutrient intakes by vulnerable children. Poverty, inadequate access to nutritious foods, limited knowledge about available micronutrient-rich foods, geographical location and intra-household food allocation, among other factors, could deny children adequate micronutrient intakes. There are also reports of socio-economic and cultural barriers to receiving micronutrient supplementation in $\operatorname{Nigeria}^{(7,16)}$, with evidence that micronutrient supplementation mostly covers the peri-urban population $^{(17)}$. According to WHO statistics, northern Nigeria with the highest burden of micronutrient deficiencies is receiving the least coverage of supplementation ${ }^{(18)}$. Furthermore, the determinants of vitamin A supplementation uptake by children differ across the six geopolitical zones of Nigeria ${ }^{(16)}$. Vitamin A deficiency disparities were observed across the Nigerian geopolitical zones and this was attributed to the effect of dietary patterns on vitamin A sources $^{(7)}$. This phenomenon continues to raise a major concern on the delivery of micronutrients to vulnerable parts of the population, with some experts advocating for more interventions towards a sustainable food-based approach to be the priority path to enhance nutrition ${ }^{(19,20)}$.

Consumption of more diverse foods over a long period has been linked to micronutrient consumption adequacy $^{(21-23)}$. While households may have some levels of access to micronutrient-rich foods, what determines adequate consumption by children may differ from that of adults $^{(24,25)}$. One factor which may hinder children from receiving adequate micronutrients from foods, but less studied empirically, relates to food distribution patterns within the household. Understanding the possible biases in food variety allocation within the household may showcase the complementary (or otherwise) role this household idiosyncratic practice could play in child nutrition outcomes. This would inform how such a practice can be accounted for in food-based nutrition programming to enhance nutrition outcomes for children. Against this background, the present study examines: (i) the determinants of households' micronutrient-rich food consumption; and (ii) whether micronutrient-rich food consumption or vitamin A supplementation or a combination of the two has a significant effect on the linear growth of children in households with different food allocation patterns.

\section{Data and methods}

\section{Survey area}

The focus of the present paper is on Kwara State. Kwara State is in the North-Central geopolitical zone of Nigeria, and shares boundaries with six other states in the North and South, resulting in rich agro-ecological diversity. More importantly, Kwara State is strategically positioned between the dry cereal-based food systems of northern and the wet root-based food systems of southern Nigeria, thus combining a rich variety of culture and dietary practices. Over $80 \%$ of Kwara State's population lives in rural areas, out of which $90 \%$ are farmers ${ }^{(26)}$. Livestock-rearing is popular in the state and farming is mostly on a small scale. According to Omotesho and Muhammad-Lawal ${ }^{(27)}$, staple foods are yam, rice and maize, with per household weekly consumption of $21 \cdot 3,5 \cdot 8$ and $5 \cdot 1 \mathrm{~kg}$, respectively. Smaller quantities of cowpeas, meat and fish are consumed weekly. Stunting prevalence is high in the state, with an average of $44.6 \%$ according to a 2011 UNICEF report $^{(28)}$ and $37.2 \%$ according to the 2013 Demographic and Health Survey ${ }^{(3)}$.

\section{Survey design}

The household survey was conducted in November 2014 in ten villages where pro-vitamin A-fortified cassava stems were introduced at the time of the survey. Multistage, targeted sampling technique was used in selecting farming households with children aged 0-59 months. The surveyed communities were predominantly divided between two ethnic communities, Nupe and Yoruba. A total of 1275 households were listed in all the villages, out of which 215 households in the Nupe community and 199 households in the Yoruba community were eligible and surveyed. In total, 414 households and 478 mother-child pairs were sampled. More details are provided in the survey's primary study ${ }^{(29)}$. For the present study, 413 households were used in analysing the determinants of micronutrient-rich food consumption, following the removal of one household with incomplete information. We also dropped fifty-nine observations on children below 6 months old since they 
are still largely on an infant diet, thereby reducing the sample size for analysis to 419 observations of children aged 6-59 months. Children in this age bracket are introduced to complementary foods from age 6 months or earlier among the study population. Data were collected on household socio-economic characteristics, agricultural production, food consumption frequency, water and sanitation, and mother and child immunization practices. The anthropometric measurements of under-five children and their mothers were taken with standardized tools and procedures.

\section{Measurement of variables}

\section{Outcome variables}

Households' micronutrient-rich food consumption is a binary variable used as outcome in the model for the determinants of micronutrient-rich food consumption by households. As this variable also served as an input to child stunting determinants, the details of its measurement are provided below. Child nutritional status (stunting) is the second outcome variable used for the determinants of stunting. The anthropometric indicator of height-for-age measures linear growth in children and was determined using the WHO child growth standards. A child with height-for-age less than 2 sD below the median height-forage measurement for the reference group is said to be stunted $^{(30)}$. Stunting is an outcome measure of chronic undernutrition in children, which also results from failure to meet micronutrient requirements. Figure 1 shows the WHO child growth standard as compared with the growth of children in the study sample.

\section{Determinant variables}

Intra-household food allocation patterns were assessed using Likert-scale questions. Caregivers were asked to rank household members based on their food allocation in the order of 'more diverse' to 'least diverse'. These were separate questions assessing diverse food allocation among male adults, diverse food allocation among female adults, and diverse food allocation among children. BMI of the mother is a measure of thinness, which is an indication of her nutritional well-being. It is expressed as the ratio of the mother's weight (in kilograms) to the square of her height (in metres). Mothers with a BMI less than $18.5 \mathrm{~kg} / \mathrm{m}^{2}$ are considered thin or underweight. Access to safe drinking-water was measured as the proportion of households that had access to improved sources of drinking-water according to safe drinking-water standards of the WHO. We measured livestock ownership by Tropical Livestock Unit (TLU) scores, as used by the FAO ${ }^{(31)}$. We computed the scores for three categories of livestock: (i) cattle/bulls, horses and camels; (ii) sheep, goats and pigs; and (iii) poultry. The TLU provides a weighing factor that is assigned to each animal based on its weight, such that a single animal that weighs $250 \mathrm{~kg}$ represents 1.0 TLU. Children who experienced episodes of both diarrhoea and malaria fever during the 2 -week period preceding the interview day were judged to be morbid.

Micronutrient intakes from foods and supplementation are the main determinants of interest in the present study. Food groups rich in vitamin A and Fe (Table 1) were used, following Kennedy et al. ${ }^{(32)}$, to assess micronutrient intakes from food sources, while vitamin A doses

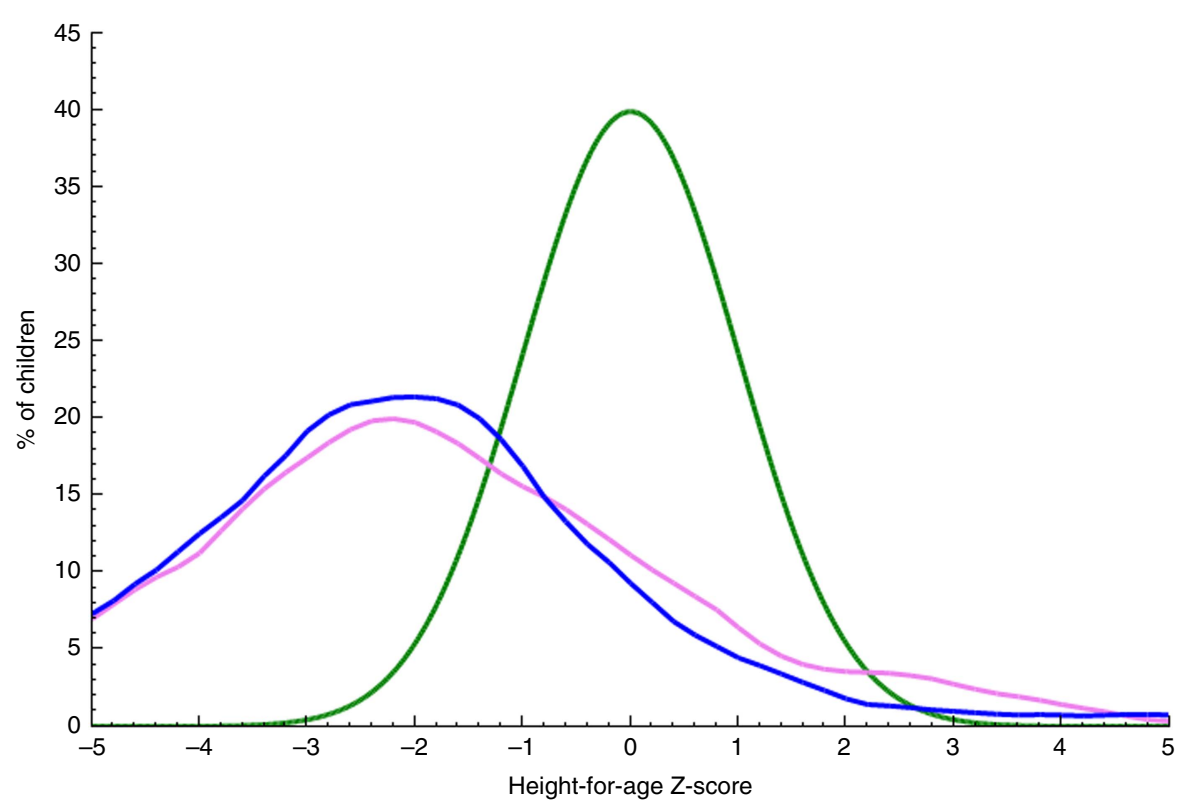

Fig. 1 (colour online) Distribution of height-for-age Z-scores of children aged 6-59 months by gender ( - , female, $n 222 ;-$ male, $n$ 208) in Kwara State, rural Nigeria, November 2014, as compared with the WHO child growth standard normal distribution curve of the reference population ( $(-)$. Plot generated from WHO Anthro software based on the survey data 
given to children measured intakes from supplementation. The proportion of children aged 6-59 months who received vitamin A (doses equal to or greater than $625 \mu \mathrm{g}$ (25000 IU)) within the last 6 months as recommended by $\mathrm{WHO}^{(33)}$ was assessed from children's immunization cards. We measured micronutrient intakes from food sources based on information collected on household food consumption frequency over a 6 -month period. The caregivers were asked, by probing from exhaustive lists of food items consumed in the area to aid their recollection, 'How often did you prepare and/or consume [food item] in the last 6 months within your household?' Caregivers' response was ordered on a scale of 0 to 5 ranging from 'not at all' to 'daily'. In total, eighteen micronutrient-rich foods were consumed (Table 2) within

Table 1 Foods used for assessing households' micronutrient-rich food consumption

\begin{tabular}{|c|c|c|}
\hline & Food group & Food items consumed by households \\
\hline 1 & $\begin{array}{l}\text { Vitamin A-rich } \\
\text { vegetables/tubers }\end{array}$ & $\begin{array}{l}\text { Carrot, pumpkin, okra, red pepper, } \\
\text { tomatoes, sweet potato }\end{array}$ \\
\hline 2 & Vitamin A-rich fruits & Ripe mango, ripe papaya, watermelon \\
\hline 3 & $\begin{array}{l}\text { Dark green leafy } \\
\text { vegetables (DGV) }\end{array}$ & $\begin{array}{l}\text { DGV, amaranth leaves, cassava leaves, } \\
\text { spinach, Moringa leaves } \dagger\end{array}$ \\
\hline 4 & Organ meat & $\begin{array}{l}\text { Liver, kidney, heart and other blood- } \\
\text { based meats }\end{array}$ \\
\hline 5 & Eggs & $\begin{array}{l}\text { Eggs from chickens, ducks, guinea fowls } \\
\text { or any other egg }\end{array}$ \\
\hline 6 & $\begin{array}{l}\text { Milk and milk } \\
\text { products }\end{array}$ & $\begin{array}{l}\text { Milk, cheese, yoghurt or other milk } \\
\text { products }\end{array}$ \\
\hline 7 & Flesh meat & $\begin{array}{l}\text { Beef, pork, lamb, goat, game, chicken, } \\
\text { duck, other birds }\end{array}$ \\
\hline $\begin{array}{l}8 \\
9\end{array}$ & $\begin{array}{l}\text { Fish and seafood } \\
\text { Dry beans }\end{array}$ & $\begin{array}{l}\text { Fresh or dried fish or shellfish } \\
\text { Including other local varieties of dry } \\
\text { beans rich in Fe }\end{array}$ \\
\hline
\end{tabular}

†Moringa oleifera is a plant native to the tropics with high micronutrient content $(5880 \mu \mathrm{g} \beta$-carotene/100 g edible portion). The leaves are cooked and used like spinach or dried and crushed into a powder for use in soups and sauces. Among the households in our sample, about $48 \%$ of them often dried Moringa leaves and used it like a micronutrient powder on foods. nine food groups that were mutually exclusive (Table 1). The percentage of households consuming micronutrientrich foods by their consumption frequency in the last 6 months is presented in Table 2. Households were scored based on their frequency of consumption of vitamin A-rich and Fe-rich foods. A household that consumed a food item daily was assigned a value of 5 , while 0 was assigned to a household that did not consume a food item. Households with more frequencies of 0 (not at all) on each food item had the least score, while households with more frequencies of 5 (daily) on each food item had the highest score. These scores were divided into low and high by their mean score to produce a binary variable for household's micronutrient-rich food consumption. We interacted this variable with the variable 'child received vitamin A supplement' and 'household members allocated more diverse diets' to produce interaction terms (variables) which are also included in the model for the determinants of child stunting. The summary statistics of the variables used are presented in Table 3 .

Using the consumption frequency of micronutrient-rich foods within the household over a 6-month period allows us to capture all possible food items consumed across seasons, as opposed to using household or child dietary diversity captured by food consumption in the previous day or over a $7 \mathrm{~d}$ period $^{(34)}$. According to Hoddinott and Yohannes ${ }^{(35)}$, household dietary diversity is not appropriate for measuring micronutrient contents of diets as it includes food groups with high energy in addition to foods rich in micronutrients.

\section{Econometric methodology}

Logistic models were specified to: (i) examine the determinants of micronutrient-rich food consumption in the

Table 2 Frequency of consumption of micronutrient-rich foods by households in Kwara State, rural Nigeria, November 2014 ( $n$ 413)

\begin{tabular}{|c|c|c|c|c|c|c|c|c|}
\hline & Micronutrient-rich food & $\begin{array}{l}\text { Not at all }(\%) \\
(\text { score }=0)\end{array}$ & $\begin{array}{l}\text { Rarely }(\%) \\
(\text { score = 1) }\end{array}$ & $\begin{array}{l}\text { Once/month }(\%) \\
\quad(\text { score }=2)\end{array}$ & $\begin{array}{l}\text { Once/week (\%) } \\
\quad(\text { score = 3) }\end{array}$ & $\begin{array}{c}2-4 \text { times/week }(\%) \\
(\text { score }=4)\end{array}$ & $\begin{array}{l}\text { Daily }(\%) \\
(\text { score }=5)\end{array}$ & Total $(\%)$ \\
\hline 1 & Milk and milk products & 4.06 & 3.34 & $15 \cdot 27$ & 35.32 & 36.99 & 5.01 & $100 \cdot 0$ \\
\hline 2 & Eggs & $2 \cdot 39$ & $3 \cdot 34$ & 17.42 & $46 \cdot 30$ & $27 \cdot 21$ & 3.34 & $100 \cdot 0$ \\
\hline 3 & Organ meat & $6 \cdot 44$ & $3 \cdot 82$ & 21.96 & 41.77 & $25 \cdot 30$ & 0.72 & $100 \cdot 0$ \\
\hline 4 & Flesh red meat & 1.43 & $1 \cdot 19$ & $10 \cdot 26$ & 27.68 & 52.98 & 6.44 & $100 \cdot 0$ \\
\hline 5 & Poultry & 8.35 & 21.96 & 45.82 & 16.47 & $7 \cdot 16$ & 0.24 & $100 \cdot 0$ \\
\hline 6 & Fish and seafood & 0.95 & 0.24 & 0.95 & 12.65 & 54.42 & 30.79 & $100 \cdot 0$ \\
\hline 7 & Spinach & 45.58 & 1.91 & 8.83 & 18.62 & 23.87 & $1 \cdot 19$ & $100 \cdot 0$ \\
\hline 8 & Cassava leaves & 93.32 & 0.95 & 1.19 & 1.19 & 3.34 & 0.00 & $100 \cdot 0$ \\
\hline 9 & Amaranth leaves & 0.00 & 19.33 & $3 \cdot 82$ & 32.46 & 43.44 & 0.95 & $100 \cdot 0$ \\
\hline 10 & Red pepper & 6.44 & 1.67 & 4.77 & $17 \cdot 18$ & $50 \cdot 84$ & 19.09 & $100 \cdot 0$ \\
\hline 11 & Sweet potato & 9.79 & 3.58 & $15 \cdot 51$ & 28.64 & 36.75 & 5.73 & $100 \cdot 0$ \\
\hline 12 & Carrot & 19.81 & 11.93 & 31.03 & 21.96 & 14.80 & 0.48 & $100 \cdot 0$ \\
\hline 13 & Fruited pumpkin & 41.05 & 3.82 & 13.37 & 27.68 & 13.37 & 0.72 & $100 \cdot 0$ \\
\hline 14 & Pumpkin & 71.36 & 5.73 & 10.98 & 4.77 & $6 \cdot 21$ & 0.95 & $100 \cdot 0$ \\
\hline 15 & Papaya & 5.73 & 12.41 & 13.37 & 31.26 & 34.61 & 2.63 & $100 \cdot 0$ \\
\hline 16 & Ripe mango & $5 \cdot 25$ & 24.11 & $15 \cdot 27$ & 15.04 & 34.61 & 5.73 & $100 \cdot 0$ \\
\hline 17 & Moringa leaves & 52.27 & 12.89 & 22.43 & 7.88 & 4.53 & 0.00 & 100.0 \\
\hline 18 & Dry beans & 5.49 & 0.72 & 4.06 & 21.00 & 62.05 & $6 \cdot 68$ & $100 \cdot 0$ \\
\hline
\end{tabular}


Table 3 Descriptive statistics and comparisons of means for variables used in the analysis of the determinants of stunting in children aged 6-59 months in Kwara State, rural Nigeria, November 2014 ( $n$ 419)

\begin{tabular}{|c|c|c|c|}
\hline Variable measurement (minimum/maximum) & Mean & SD & Mean comparison† \\
\hline Child is stunted $(\mathrm{HAZ}<-2.0)(0 / 1)$ & 0.56 & 0.50 & \\
\hline Household consumed MRF (0/1) & 0.44 & 0.50 & $0 \cdot 13^{\star \star \star}$ \\
\hline Child received VAS $(0 / 1)$ & 0.37 & 0.48 & $-0.06^{\star}$ \\
\hline Children allocated more diverse diets $(0 / 1)$ & 0.37 & 0.48 & -0.02 \\
\hline Female adults allocated more diverse diets $(0 / 1)$ & $0 \cdot 15$ & 0.36 & 0.03 \\
\hline Male adults allocated more diverse diets $(0 / 1)$ & 0.48 & 0.50 & -0.01 \\
\hline Household consumed MRF $\times$ child received VAS $(0 / 1)$ & $0 \cdot 21$ & 0.41 & 0.02 \\
\hline Household consumed MRF × children allocated more diverse diets $(0 / 1)$ & 0.22 & 0.42 & 0.05 \\
\hline Household consumed MRF $\times$ female adults allocated more diverse diets $(0 / 1)$ & 0.05 & $0 \cdot 22$ & 0.02 \\
\hline Household consumed MRF $\times$ male adults allocated more diverse diets $(0 / 1)$ & $0 \cdot 23$ & 0.42 & $0 \cdot 06^{*}$ \\
\hline Owns cattle, horses and camels (TLU) $(0 / 15)$ & 0.47 & 2.04 & $-0.42^{\star \star}$ \\
\hline Owns sheep, goats and pigs (TLU) $(0 / 5 \cdot 5)$ & 0.38 & 0.63 & 0.01 \\
\hline Owns chicken and geese (TLU) $(0 / 10)$ & 0.41 & 0.69 & -0.02 \\
\hline Has access to improved drinking-water $(0 / 1)$ & 0.59 & 0.49 & 0.02 \\
\hline Has a refrigerator $(0 / 1)$ & 0.23 & 0.42 & $0 \cdot 10^{\star \star *}$ \\
\hline Nupe community $(0 / 1)$ & 0.55 & 0.50 & $-0 \cdot 24^{\star \star *}$ \\
\hline Number of household members (2/20) & $6 \cdot 87$ & $3 \cdot 81$ & $-1.55^{\star \star \star}$ \\
\hline Mother has no education $(0 / 1)$ & 0.63 & 0.48 & $-0 \cdot 17^{\star \star \star}$ \\
\hline Mother has at least primary-level education (0/1) & $0 \cdot 17$ & 0.38 & 0.02 \\
\hline Mother has at least secondary-level education (0/1) & $0 \cdot 20$ & 0.40 & $0 \cdot 15^{\star \star \star}$ \\
\hline Mother's $\mathrm{BMI}<18.5 \mathrm{~kg} / \mathrm{m}^{2}(0 / 1)$ & 0.07 & 0.26 & 0.01 \\
\hline Mother's age in years $(23 / 85)$ & 41.82 & 11.08 & 0.79 \\
\hline Boy child $(0 / 1)$ & 0.49 & 0.50 & -0.04 \\
\hline Child has no morbidity $(0 / 1)$ & 0.63 & 0.48 & 0.06 \\
\hline Child's age (6-11 months) (0/1) & $0 \cdot 14$ & 0.34 & 0.01 \\
\hline Child's age (12-23 months) $(0 / 1)$ & 0.33 & 0.47 & 0.01 \\
\hline Child's age (24-35 months) (0/1) & 0.27 & 0.44 & 0.02 \\
\hline Child's age (36-59 months) (0/1) & 0.26 & 0.44 & -0.04 \\
\hline
\end{tabular}

HAZ, height-for-age Z-score; MRF, micronutrient-rich foods; VAS, vitamin A supplement; TLU, Tropical Livestock Unit.

†Level of significance of the difference in outcome/characteristic between stunted and non-stunted children based on independent-sample $t$ tests: ${ }^{*} 10 \%$ level of significance $(P<0.1),{ }^{\star \star} 5 \%$ level of significance $(P<0.05),{ }^{\star \star \star} 1 \%$ level of significance $(P<0.01)$.

households; and (ii) analyse the factors that can influence the likelihood of child stunting among households. Logistic regression is a binary dependent outcome in which the outcome variable assumes only two values such as 1 or 0 ; in this case (i) whether the household consumed micronutrient-rich food or not and (ii) whether the child is stunted or not. The model specification for the determinants of micronutrient-rich food consumption is different from the model specification regarding stunting determinants. Their specifications were both informed by literature on household food availability and accessibility, and the framework on child malnutrition. For the determinants of stunting, we controlled for diverse food allocation preference among household members (children, female adults or male adults) to account for the differences in food allocation patterns among the households. Other control variables were: household characteristics such as household size, refrigerator ownership, access to improved drinking-water and livestock holdings expressed in TLU; caregiver characteristics such as education level, age and BMI; and child characteristics including sex, morbidity status and age. We used the statistical software package Stata version 15, with which we were able to adjust the se for the two community clusters to obtain more robust SE. Also, for the purposes of reporting policy implications of the results, we generated the marginal effect for the results.
Table 4 Micronutrient intakes, intra-household food allocation and stunting prevalence in children aged 6-59 months in Kwara State, rural Nigeria, November 2014 ( $n$ 419)

\begin{tabular}{lc}
\hline Variable & $\begin{array}{c}\text { Percentage of the } \\
\text { sample }\end{array}$ \\
\hline HAZ<-2.0 (stunting) & 55.85 \\
Household consumed MRF & 43.68 \\
Child received VAS & 36.52 \\
Child received MRF and VAS & 20.76 \\
Children allocated more diverse diets & 36.99 \\
Female adults allocated more diverse & 15.04 \\
$\quad$ diets & 47.97
\end{tabular}

HAZ, height-for-age Z-score; MRF, micronutrient-rich foods; VAS, vitamin A supplement.

\section{Results}

\section{Descriptive results}

Tables 3 and 4 present the descriptive results of the key variables. The prevalence of stunting was very high (55.85\%) among under-five children in the study population. Children from households that consumed micronutrient-rich foods comprised $43.68 \%$, while $36.52 \%$ of the children had received vitamin A supplement in the last 6 months, and only $20.76 \%$ seemed to have access to micronutrients from both foods and supplementation. In 
terms of intra-household food allocation, only $37 \%$ of the children belonged to households where preference was given to children, and few (15\%) children resided in households where female adults received more diverse food. About half of the children were from households that allocated more diverse food to male adults. Most cattle were owned by the Nupe community among whom are the Fulanis who are famous for cattle-rearing, while small livestock (chicken, sheep and goats) were mainly owned by the Yoruba community. The mean frequency of micronutrient-rich food consumption among the Nupe community was greater than that among the Yoruba community (Fig. 2), while the total mean for all the sample was normally distributed (Fig. 3). About $80 \%$ of the sampled households owned poultry, while only $70 \%$ of them occasionally consumed poultry and fewer consumed poultry eggs. Education level attainment was lower for mothers than fathers, with about $63 \%$ of mothers having no formal education while just $29 \%$ of fathers had never attended school.

\section{Econometric results}

The regression outputs in Table 5 show the determinants of households' micronutrient-rich food consumption. Ownership of poultry $(P<0 \cdot 01)$, awareness of micronutrient-rich foods $(P<0 \cdot 01)$ and father's education from primary school level and beyond $(P<0.01)$ each had a positive and statistically significant effect on the likelihood of micronutrientrich food consumption. Ownership of a refrigerator $(P<0.05)$ was also positively associated with micronutrientrich food consumption. Ownership of small ruminants (sheep, goats and pigs; $P<0.05)$ and mother's age $(P<0 \cdot 1)$ showed a negative association with micronutrient-rich food consumption.

The regression results of the determinants of child stunting are presented in Table 6. Households that consumed micronutrient-rich foods, those that combined consumption of micronutrient-rich foods with vitamin A supplementation for children, and households consuming micronutrient-rich foods but biasing diverse food allocation in favour of children reduced the likelihood of child stunting respectively by $0.106(P<0.01), 0.042$ $(P<0.05)$ and $0.067(P<0.10)$ points. Households that owned small ruminants $(P<0 \cdot 01)$ and those in which mothers had secondary education $(P<0 \cdot 01)$ had lower chance of having stunted children. Households in which children did not experience morbidity $(P<0.05)$ and those that possessed a refrigerator $(P<0.05)$ had lower probability of experiencing child stunting. The child belonging to a household with large size (members) or the Nupe community had increased probability of stunting by $0.02(P<0.01)$ and $0.13(P<0.01)$ points, respectively.

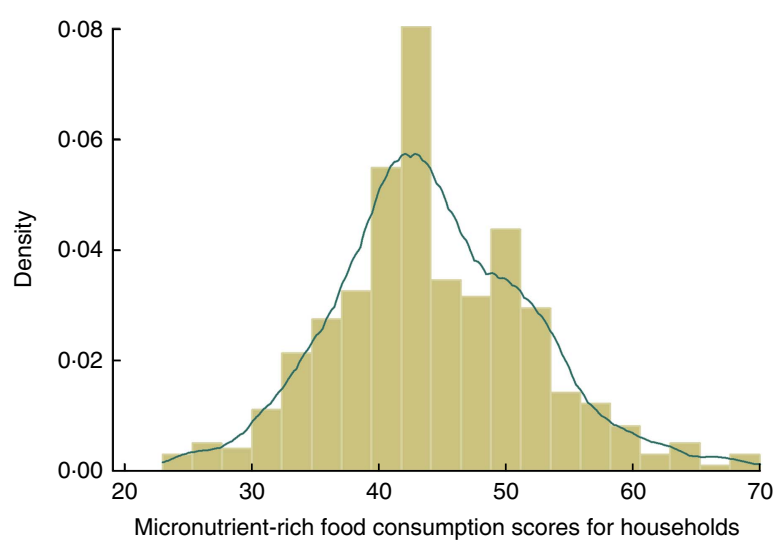

Fig. 3 (colour online) Distribution ( $\square$, density plot; - , kernel density plot) of households' micronutrient-rich food consumption frequency score in Kwara State, rural Nigeria, November 2014 (n 413)

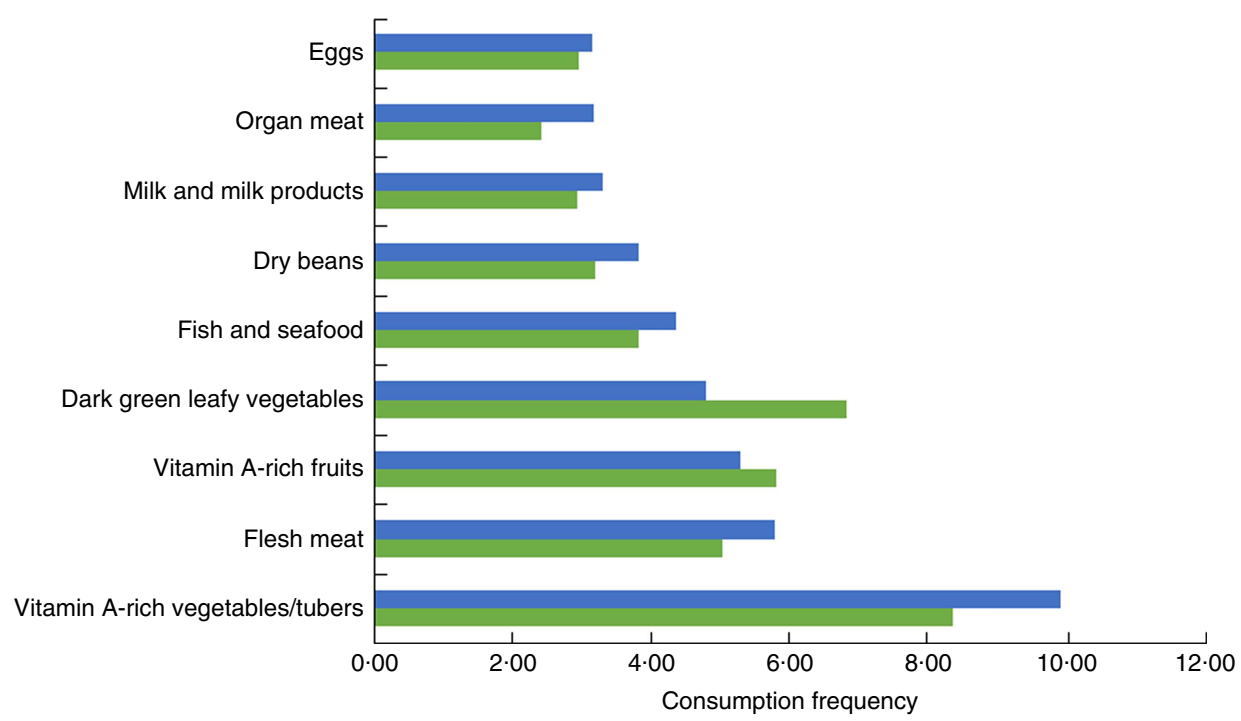

Fig. 2 (colour online) Mean frequency of consumption of micronutrient-rich food groups by households located in Nupe ( $\square$ ) and Yoruba communities $(\square)$ in Kwara State, rural Nigeria, June to November 2014 (n 413) 
Table 5 Logistic results of the determinants of households' consumption of micronutrient-rich foods in Kwara State, rural Nigeria, November 2014 ( $n$ 413)

\begin{tabular}{|c|c|c|c|c|c|}
\hline \multirow[b]{2}{*}{ Micronutrient-rich food consumption } & \multirow[b]{2}{*}{ OR } & \multirow[b]{2}{*}{ SE } & \multirow[b]{2}{*}{$95 \% \mathrm{Cl}$} & \multicolumn{2}{|c|}{ Marginal effects $†$} \\
\hline & & & & $\mathrm{d} y / \mathrm{d} x$ & SE \\
\hline Owns cattle, horses and camels (TLU) & 0.96 & 0.03 & $0.90,1.01$ & -0.01 & 0.01 \\
\hline Owns sheep, goats and pigs (TLU) & $0.91^{\star \star}$ & 0.04 & $0.83,1.00$ & $-0.02^{\star \star}$ & 0.01 \\
\hline Owns chicken and geese (TLU) & $1.37^{\star \star \star}$ & 0.11 & $1.18,1.59$ & $0.07^{\star * *}$ & 0.02 \\
\hline Farming is household primary activity & 0.95 & 0.07 & $0.82,1.10$ & -0.01 & 0.02 \\
\hline Aware of micronutrient-rich foods & $3.86^{\star \star \star}$ & 0.29 & $3.36,4.48$ & $0.29^{\star \star \star}$ & 0.01 \\
\hline Household owns a refrigerator & $1.65^{\star *}$ & 0.38 & $1.06,2.59$ & $0 \cdot 11^{\star *}$ & 0.05 \\
\hline Household owns a radio & 1.54 & 0.62 & $0.69,3.39$ & 0.09 & 0.09 \\
\hline Nupe community & 0.93 & 0.18 & $0.64,1.36$ & -0.02 & 0.04 \\
\hline Number of household members & 0.99 & 0.08 & $0.86,1.15$ & -0.00 & 0.02 \\
\hline Mother's age in years & $0.96^{*}$ & 0.01 & $0.97,1.00$ & $-1.2 \times 10^{-6 *}$ & $2.4 \times 10^{-7}$ \\
\hline Mother has at least primary-level education & 1.20 & 0.24 & $0.81,1.78$ & 0.04 & 0.04 \\
\hline Mother has at least secondary-level education & 1.13 & 0.11 & $0.93,1.37$ & 0.03 & 0.02 \\
\hline Father has at least primary-level education & $3.13^{\star \star *}$ & 0.11 & $2.92,3.35$ & $0.25^{\star \star \star}$ & 0.01 \\
\hline Father has at least secondary-level education & $2 \cdot 37^{\star \star \star}$ & 0.64 & $1.39,4.01$ & $0.19^{\star \star \star}$ & 0.06 \\
\hline Constant & $0.35^{\star \star \star}$ & 0.15 & $0.15,0.80$ & & \\
\hline Pseudo $R^{2}$ & 0.094 & & & & \\
\hline Log pseudolikelihood & -256.58 & & & & \\
\hline
\end{tabular}

TLU, Tropical Livestock Unit.

Robust SE adjusted for the two community clusters.

†Results reported as marginal effects: ${ }^{*} 10 \%$ level of significance $(P<0.1),{ }^{\star \star} 5 \%$ level of significance $(P<0.05)$, ${ }^{* \star} 1 \%$ level of significance $(P<0.01)$.

Table 6 Logistic regression results of the determinants of stunting in children in children aged 6-59 months in Kwara State, rural Nigeria, November 2014 ( $n$ 419)

\begin{tabular}{|c|c|c|c|c|c|}
\hline \multirow[b]{2}{*}{ Stunting $(\mathrm{HAZ}<-2)$} & \multirow[b]{2}{*}{ OR } & \multirow[b]{2}{*}{ SE } & \multirow[b]{2}{*}{$95 \% \mathrm{Cl}$} & \multicolumn{2}{|c|}{ Marginal effects $†$} \\
\hline & & & & $\mathrm{d} y / \mathrm{d} x$ & SE \\
\hline Household consumed MRF & $0.61^{* \star *}$ & 0.01 & $0.58,0.64$ & $-0 \cdot 11^{\star \star \star}$ & 0.01 \\
\hline Child received VAS & 1.99 & 0.89 & $0.83,4.82$ & 0.15 & 0.09 \\
\hline Children allocated more diverse diets & 1.54 & 0.83 & $0.54,4.43$ & 0.09 & $0 \cdot 11$ \\
\hline Female adults allocated more diverse diets & 0.76 & 0.19 & $0.46,1.25$ & -0.06 & 0.05 \\
\hline Household consumed MRF $\times$ child received VAS & $0.82^{\star \star}$ & 0.07 & $0.69,0.98$ & $-0.04^{\star *}$ & 0.02 \\
\hline Household consumed MRF × children allocated more diverse diets & $0.73^{\star}$ & $0 \cdot 13$ & $0.51,1.04$ & $-0.07^{\star}$ & 0.04 \\
\hline Household consumed MRF $\times$ female adults allocated more diverse diets & 1.49 & 0.53 & $0.74,2.97$ & 0.08 & 0.08 \\
\hline Cattle, horses and camels (TLU) & $1 \cdot 17^{\star \star}$ & 0.07 & $1.03,1.32$ & $0.03^{\star \star}$ & 0.01 \\
\hline Sheep, goats and pigs (TLU) & $0.57^{\star \star \star}$ & 0.05 & $0.48,0.67$ & $-0.12^{\star \star \star}$ & 0.02 \\
\hline Chicken and geese (TLU) & 1.19 & 0.27 & $0.76,1.86$ & 0.04 & 0.05 \\
\hline Access to improved drinking-water & 1.09 & $0 \cdot 10$ & $0.91,1.32$ & 0.02 & 0.02 \\
\hline Household has refrigerator & $0.71^{\star \star}$ & $0 \cdot 12$ & $0.52,0.98$ & $-0.07^{\star \star}$ & 0.03 \\
\hline Nupe community & $1.85^{\star \star *}$ & 0.01 & $1.83,1.86$ & $0 \cdot 13^{\star \star \star}$ & 0.00 \\
\hline Number of household members & $1 \cdot 10^{\star \star \star}$ & 0.03 & $1.05,1.16$ & $0.02^{\star \star \star}$ & 0.01 \\
\hline Mother completed primary education & 0.95 & 0.21 & $0.62,1.45$ & -0.01 & 0.05 \\
\hline Mother completed secondary education & $0 \cdot 64^{\star \star *}$ & 0.02 & $0.60,0.68$ & $-0.09^{\star \star \star}$ & 0.01 \\
\hline Mother is underweight & 0.89 & 0.37 & $0.40,2.01$ & -0.02 & 0.09 \\
\hline Mother's age in years & 1.00 & 0.01 & $0.98,1.01$ & $1.3 \times 10^{-5}$ & $1.2 \times 10^{-7}$ \\
\hline Boy child & 1.33 & 0.26 & $0.91,1.95$ & 0.06 & 0.04 \\
\hline Child did not experience morbidity & $0.62^{\star \star}$ & 0.15 & $0.39,1.01$ & $-0 \cdot 10^{\star \star}$ & 0.05 \\
\hline Child's age (6-11 months) & 0.91 & 0.07 & $0.78,1.06$ & -0.02 & 0.02 \\
\hline Child's age (12-23 months) & 0.86 & 0.36 & $0.38,1.97$ & -0.03 & 0.09 \\
\hline Child's age (24-35 months) & 1.06 & 0.39 & $0.51,2 \cdot 21$ & 0.01 & 0.08 \\
\hline Constant & 0.72 & 0.19 & $0.44,1.19$ & & \\
\hline Pseudo $R^{2}$ & 0.12 & & & & \\
\hline Log pseudolikelihood & -256.59 & & & & \\
\hline
\end{tabular}

HAZ, height-for-age Z-score; MRF, micronutrient-rich foods; VAS, vitamin A supplement; TLU, Tropical Livestock Unit.

Robust SE adjusted for the two community clusters.

†Results reported as marginal effects: ${ }^{*} 10 \%$ level of significance $(P<0.1),{ }^{\star *} 5 \%$ level of significance $(P<0.05),{ }^{* * *} 1 \%$ level of significance $(P<0.01)$.

\section{Discussion}

From our results, knowledge of micronutrient-rich foods, owning a refrigerator, keeping poultry and high level of father's education all determine households' consumption of micronutrient-rich foods. The study by Block ${ }^{(36)}$ shows that nutritional knowledge increases household demand for micronutrient-rich foods in Indonesia, and 
parental education has been shown to increase households' consumption of micronutrient-rich foods ${ }^{(37)}$. Owning a refrigerator may give household regular access to some perishable foods, such as fruits and vegetables, meat and dairy products, which are rich in micronutrients. The negative association between owning small ruminants and micronutrient-rich food consumption could be that these animals are usually kept for purposes other than consumption. However, further investigation into the effect of owning small ruminants on child nutrition outcomes suggests that these animals can significantly reduce the probability of stunting in children. We therefore deduced that the influence of owning small ruminants on child nutrition outcome (stunting) could be through the income pathway, with such income not being used to purchase food items, but rather spent on non-food items that are of nutritional benefits for children such as child health care or water and sanitation items. While this result will require further investigation, evidence from Uganda shows that owning small ruminants is not associated with goat and sheep meat consumption and stunting reduction ${ }^{(38)}$. These factors, if taken into consideration in nutrition interventions, could ensure households (children) have adequate access to micronutrient-rich foods.

The present study also finds that vitamin A supplementation to children alone is not statistically significantly associated with the probability of stunting reduction. This may be an indication that children are also lacking other micronutrients such as $\mathrm{Zn}$, given that $\mathrm{Zn}$ deficiency in children inhibits growth and reduces children's ability to utilize vitamin A from supplementation ${ }^{(12)}$. Therefore, administration of vitamin A supplement (single micronutrient) alone may not guarantee a significant increase in children's vitamin A levels and stunting reduction. However, the marginal effect result suggests that the predicted probability of stunting is lower by 0.04 points for the child who receives vitamin A supplementation in a household that consumes micronutrient-rich foods as compared with a child who does not receive the supplementation (although from a similar household). Even though high consumption of micronutrient-rich foods has a strong influence on the likelihood of stunting reduction, the influence will be stronger if it favours a child to receive vitamin A supplementation or multiple micronutrient supplementation in addition to consuming micronutrient-rich foods, especially for the extremely vulnerable children. While the finding projects the significance of micronutrient intakes from food sources as a long-term strategy in reducing micronutrient malnutrition in Nigeria and in Africa, it also shows that multiple micronutrient supplementation could be a short-term measure. For example, evidence from an efficacy test conducted in South Africa revealed that fortification of biscuits with $\mathrm{Fe}, \beta$-carotene and iodine improved the status of all these nutrients in schoolchildren, but during the long school holidays vitamin $\mathrm{A}$ and Fe status deteriorated when the biscuits were not fed to the children ${ }^{(39)}$.

With respect to intra-household food allocation, our results show that the probability of escaping child stunting is higher among households that give children more diverse diets including micronutrient-rich foods as compared with households in which greater preference is given to male or female adults in terms of food diversity. Evidence from South Asia and Africa ${ }^{(40)}$ shows that the nutritional needs of men, women, boys and girls are often socially constructed based on culture. Also, it is common practice for women to eat after everyone else has eaten at a meal, and women and children are less likely than men in the same household to consume preferred foods such as meat and fish ${ }^{(41)}$. Giving preference to children in terms of food allocation is an indication of adequate child care which is critical for enhancing child well-being. Nutrition education for mothers as well as fathers of children on good infant and young child feeding practices should be emphasized as a complementary policy pathway to child stunting reduction.

The descriptive results show that households in the Nupe community have more access to consumption of micronutrient-rich foods, are predominantly farmers and are less educated. An average child from the Nupe community is more likely to become stunted compared with an average child from the Yoruba community. Their cultural inclinations and consumption habits may differ from other communities, which may have an effect on childcare practices, food choices and, by extension, the nutritional status of children from the locality, given also that stunting is influenced by multiple factors in addition to inadequate $\operatorname{diets}^{(4)}$. Studies that have established the influence of culture or spatial location on household food access and child nutrition include that of Nana et al. ${ }^{(42)}$ in rural Burkina Faso, Agada and Igbokwe ${ }^{(43)}$ and Amare et al. ${ }^{(44)}$ in northern Nigeria, and Pawloski et al. ${ }^{(45)}$ in Kenya. A child born to a mother who has up to secondary school education has a better chance of not experiencing stunting. The influence of education on child nutrition outcomes has been documented by Webb and Block ${ }^{(46)}$ and Makoka $^{(47)}$. Another study in Kwara State found a statistically significant influence of mother's education on child nutrition outcomes ${ }^{(48)}$. An average child who does not experience morbidity has lower probability of stunting. The experience of stunting is more likely to be common among children from age 12 months and above. This might be related to the fact that more general attention is usually given to an infant child than to relatively older ones.

Furthermore, the results show that ownership of cattle, horses and camels can increase the probability of child stunting. Livestock ownership is supposed to contribute to child nutritional well-being through household consumption of animal-source foods and income from sales of 
animals, which may be used to purchase other food and non-food items ${ }^{(49)}$. The positive association of holding cattle, horses and camels with stunting suggests that rural households keep these animals mainly for generating income. The descriptive result shows that less than $8 \%$ of consumption is associated with the consumption of products from these animals. It is therefore unlikely that income generated from keeping cattle, horses and camels was channelled to purchasing nutritious foods for the household members or other non-food items that are of nutritional benefits for children. On the other hand, small livestock like poultry, sheep, goats and pigs seem to have some advantages over large livestock given that the production cycle is shorter, they are mostly kept by women and are kept more for household consumption, especially poultry, than for income generation ${ }^{(49)}$. It could be inferred from the above result that promoting small livestock holdings could be a strategy for accelerating stunting reduction through consumption or through income that is channelled towards food or nonfood items that are valuable for child nutritional wellbeing. Although keeping poultry shows a significant effect on the probability of households' micronutrientrich food consumption, no such effect on the probability of stunting reduction in children is apparent. Poor management practices in poultry-keeping may be responsible for this result. A study in Ethiopia by Headey and Hirvonen $^{(50)}$ found that stunting rates in children belonging to households that kept chickens indoors overnight was $6 \%$ higher than in households where chickens were kept outside at night. Needless to say, further work is required to understand these dynamics and to substantiate these findings further.

\section{Conclusions}

In conclusion, the present study reveals that the more frequently a household consumes micronutrient-rich foods, the more likely children who belong to that household will receive diets that help meet their daily micronutrient needs. Micronutrient supplementation to children with poor access to micronutrient-rich foods may not substantially enhance child growth unless reinforced through consumption of micronutrient-rich foods. Also, access to micronutrient-rich foods may not translate into a reduction in child stunting in some communities, which is the case of Nupe community in the present study. Children are also likely to increase micronutrient intakes if parents give preference to them in terms of diverse food allocation, including micronutrient-rich foods. We also found that households holding small livestock have the potential to increase access to and consumption of micronutrientrich foods, including animal-source foods, but rearing small livestock, especially poultry, should be such that would not negate the nutrition benefit to children. On the policy front, interventions that promote such practices as home fruit and vegetable gardening and small livestock holdings might significantly increase micronutrient intakes and reduce child stunting among vulnerable households. Finally, nutrition education to parents on practices that could increase their children's micronutrient intakes from food should be integrated into development policies and programmes.

\section{Acknowledgements}

Acknowledgements: The authors are grateful for the valuable comments and contributions received at the $3 \mathrm{rd}$ International Conference on Global Food Security in Cape Town, South Africa, where the study was presented. They would like also to thank the research team of IFPRI's Nigeria Strategy Support Program (NSSP) for helpful comments and suggestions on an earlier version of this paper presented in a Brown Bag Seminar at the IFPRI Nigeria Office in Abuja, Nigeria. Valuable comments on an earlier version were also received from Oluyemisi Kuku. Any remaining errors are the responsibility of the authors alone. Financial support: This study is based on earlier research work at the International Food Policy Research Institute (IFPRI) Abuja Office which was funded by the Department for International Development (DFID) UK. DFID had no role in the design, analysis or writing of this article. Conflict of interest: None. Authorship: O.F., G.M., D.A. and O.M. formulated the research questions, designed and carried out the study under also the general supervision of G.M., who provided the essential research material and advised the research team throughout. O.F. and D.A. analysed the data. All authors were involved in writing the manuscript, and all read and approved the final manuscript. O.F. and G.M. had primary responsibility for the final content. Ethics of human subject participation: This study was conducted according to the guidelines laid down in the Declaration of Helsinki and all procedures involving human subjects were approved by the Institutional Review Board (IRB) of IFPRI (IRB No. 00007490, FWA 00005121). Written informed consent was obtained from all subjects.

\section{References}

1. International Food Policy Research Institute (2017) 2017 Global Food Policy Report. Washington, DC: IFPRI; available at https://www.doi.org/10.2499/9780896292529

2. International Food Policy Research Institute (2014) Global Nutrition Report 2014: Actions and Accountability to Accelerate the World's Progress on Nutrition. Washington, DC: IFPRI.

3. National Population Commission \& ICF International (2014) Nigeria Demographic and Health Survey 2013. Abuja and Rockville, MD: NPC and ICF International.

4. UNICEF (2013) Improving Child Nutrition: The Achievable Imperative for Global Progress. New York: UNICEF. 
5. Akerele D, Sanusi RA, Fadare OA et al. (2017) Factors influencing nutritional adequacy among rural households in Nigeria: how does dietary diversity stand among influencers? Ecol Food Nutr 56, 187-203.

6. Beal T, Massiot E, Arsenault JE et al. (2017) Global trends in dietary micronutrient supplies and estimated prevalence of inadequate intakes. PLoS One 12, e0175554.

7. Maziya-Dixon BB, Akinyele IO, Sanusi RA et al. (2006) Vitamin A deficiency is prevalent in children less than $5 \mathrm{y}$ of age in Nigeria. J Nutr 136, 2255-2261.

8. Rao S, Yajnik CS, Kanade A et al. (2001) Intake of micronutrient-rich foods in rural Indian mothers is associated with the size of their babies at birth: Pune Maternal Nutrition Study. J Nutr 131, 1217-1224.

9. Ramakrishnan U, Aburto N, McCabe G et al. (2004) Multimicronutrient interventions but not vitamin A or iron interventions alone improve child growth: results of 3 metaanalyses. J Nutr 134, 2592-2602.

10. Ramakrishnan U, Nguyen P \& Martorell R (2009) Effects of micronutrients on growth of children under $5 \mathrm{y}$ of age: meta-analyses of single and multiple nutrient interventions. Am J Clin Nutr 89, 191-203.

11. Sachdev HPS, Gera T \& Nestel P (2006) Effect of iron supplementation on physical growth in children: systematic review of randomized controlled trials. Public Health Nutr 9, 904-920.

12. Imdad A \& Bhutta ZA (2011) Effect of preventive zinc supplementation on linear growth in children under 5 years of age in developing countries: a meta-analysis of studies for input to the lives saved tool. BMC Public Health 11, Suppl. 3, S22.

13. Kyu HH, Pinho C, Wagner JA et al. (2016) Global and national burden of diseases and injuries among children and adolescents between 1990 and 2013: findings from the Global Burden of Disease 2013 Study. JAMA Pediatr 170, 267-287.

14. World Health Organization (2006) Guidelines on Food Fortification with Micronutrients. Geneva: WHO.

15. Rahman MM, Wahed MA, Fuchs GJ et al. (2002) Synergistic effect of zinc and vitamin A on the biochemical indexes of vitamin A nutrition in children. Am J Clin Nutr 75, 92-98.

16. Aremu O, Lawoko S \& Dalal K (2010) Childhood vitamin A capsule supplementation coverage in Nigeria: a multilevel analysis of geographic and socioeconomic inequities. Scientific WorldJournal 10, 1901-1914.

17. Stoltzfus RJ, Heidkamp R \& Kenkel D (2007) Iron supplementation of young children: learning from the new evidence. Food Nutr Bull 28, Suppl. 4, S572-S584.

18. World Health Organization (2017) Global Health Observatory (GHO) indicator views. http://apps.who.int/gho/data/ view.main.SUBREGprevcare-NGA (accessed February 2018).

19. Thompson B \& Amoroso L (editors) (2011) Combating Micronutrient Deficiencies: Food-Based Approaches. Rome: $\mathrm{FAO}$ and CABI.

20. Thompson B \& Amoroso L (editors) (2014) Improving Diets and Nutrition: Food-Based Approaches. Rome: FAO and CABI.

21. Moursi MM, Arimond M, Dewey KG et al. (2008) Dietary diversity is a good predictor of the micronutrient density of the diet of 6- to 23-month-old children in Madagascar. J Nutr 138, 2448-2453.

22. Lim SS, Vos T, Flaxman AD et al. (2012) A comparative risk assessment of burden of disease and injury attributable to 67 risk factors and risk factor clusters in 21 regions, 1990-2010: a systematic analysis for the Global Burden of Disease Study 2010. Lancet 380, 2224-2260.
23. Workicho A, Belachew T, Feyissa GT et al. (2016) Household dietary diversity and animal source food consumption in Ethiopia: evidence from the 2011 Welfare Monitoring Survey. BMC Public Health 16, 1192.

24. Akerele D (2011) Intra-household food distribution patterns and calorie inadequacy in South-Western Nigeria. Int $J$ Consum Stud 35, 545-551.

25. Harris-Fry H, Shrestha N, Costello A et al. (2017) Determinants of intra-household food allocation between adults in South Asia - a systematic review. Int J Equity Health 16, 107.

26. National Bureau of Statistics (2012) Consumption Patterns in Nigeria 2009/10. Abuja: NBS.

27. Omotesho OA \& Muhammad-Lawal A (2010) Optimal food plan for rural households' food security in Kwara State, Nigeria: the goal programming approach. J Agric Biotech Sustain Dev 2, 7.

28. UNICEF (2011) Multiple Indicator Cluster Survey (MICS). https://www.mics.unicef.org (accessed February 2018).

29. Kuku-Shittu O, Onabanjo O, Fadare O et al. (2016) Child malnutrition in Nigeria: Evidence from Kwara State. NSSP Working Paper no. 33. Abuja: International Food Policy Research Institute.

30. de Onis M, Garza C, Onyango AW et al. (2007) Comparison of the WHO child growth standards and the CDC 2000 growth charts. J Nutr 137, 144-148.

31. Food and Agriculture Organization of the United Nations (2011) World Livestock 2011 - Livestock in Food Security, pp. 93-94. Rome: FAO.

32. Kennedy G, Ballard T \& Dop MC (2011) Guidelines for Measuring Household and Individual Dietary Diversity. Rome: FAO.

33. World Health Organization (2016) eLENA (e-Library of Evidence for Nutrition Actions). http://www.who.int/elena/ en/ (accessed February 2016).

34. Hirvonen K, Hoddinott J, Minten B et al. (2017) Children's diets, nutrition knowledge, and access to markets. World Dev 95, 303-315.

35. Hoddinott J \& Yohannes Y (2002) Dietary Diversity as a Food Security Indicator. Washington, DC: Food and Nutrition Technical Assistance Project, Academy for Educational Development.

36. Block SA (2004) Maternal nutrition knowledge and the demand for micronutrient-rich foods: evidence from Indonesia. J Dev Stud 40, 82-105.

37. Fernández-Alvira JM, Mouratidou $\mathrm{T}$, Bammann $\mathrm{K}$ et al. (2013) Parental education and frequency of food consumption in European children: the IDEFICS study. Public Health Nutr 16, 487-498.

38. Azzarri C, Zezza A, Haile B et al. (2015). Does livestock ownership affect animal source foods consumption and child nutritional status? Evidence from rural Uganda. J Dev Stud 51, 1034-1059.

39. Van Stuijvenberg ME, Dhansay MA, Smuts CM et al. (2001) Long-term evaluation of a micronutrient-fortified biscuit used for addressing micronutrient deficiencies in primary school children. Public Health Nutr $\mathbf{4}$, 1201-1209.

40. Alderman H (2005) Linkages between poverty reduction strategies and child nutrition: an Asian perspective. Econ Polit Wkly 40, 4837-4842.

41. Wheeler EF (1991) Intra-household food and nutrient allocation. Nutr Res Rev 4, 69-81.

42. Nana CP, Brouwer ID, Zagré NM et al. (2005) Community assessment of availability, consumption, and cultural acceptability of food sources of (pro) vitamin A: toward the development of a dietary intervention among 
preschool children in rural Burkina Faso. Food Nutr Bull 26, 356-365.

43. Agada M \& Igbokwe E (2016) Influence of food culture and practices on household food security in north central Nigeria. J Food Sec 4, 36-41.

44. Amare M, Benson T, Fadare O et al. (2018) Study of the determinants of chronic malnutrition in northern Nigeria: quantitative evidence from the Nigeria Demographic and Health Surveys. Food Nutr Bull 39, 296-314.

45. Pawloski LR, Curtin KM, Gewa C et al. (2012) Maternalchild overweight/obesity and undernutrition in Kenya: a geographic analysis. Public Health Nutr 15, 2140-2147.

46. Webb P \& Block S (2003) Nutrition Knowledge and Parental Schooling as Inputs to Child Nutrition in the Long and Short Run. Working Paper no. 21. Washington, DC: USAID/DAI Food Policy Advisory Team.

47. Makoka D (2013) The Impact of Maternal Education on Child Nutrition: Evidence from Malawi, Tanzania, and Zimbabwe. Calverton, MD: ICF International.

48. Babatunde RO, Olagunju FI, Fakayode SB et al. (2011) Prevalence and determinants of malnutrition among underfive children of farming households in Kwara State, Nigeria. J Agric Sci 3, 173-181.

49. Wong JT, de Bruyn J, Bagnol B et al. (2017) Small-scale poultry and food security in resource-poor settings: a review. Glob Food Sec 15, 43-52.

50. Headey D \& Hirvonen K (2016) Is exposure to poultry harmful to child nutrition? An observational analysis for rural Ethiopia. PLoS One 11, e0160590. 